\title{
On the Performance Evaluation Criteria for the High-Tech Industrial Clusters in Leshan Based on DEA
}

\author{
Yuying Du \\ The Engineering \& Technical College of Chengdu University of Technology, \\ Leshan, Sichuan, China, 999078 \\ E-mail:512316180@qq.com
}

\begin{abstract}
Based on the features of the high technology enterprises in Leshan and DEA, this paper is to probe into the performance evaluation criteria for the high-technology industrial clusters, so that it will provide some useful advice for the development of the high technology enterprise clusters in Leshan.
\end{abstract}

Keywords- DEA; High Technology Enterprise; Industrial Clusters;Performance Evaluation

\section{INTRODUCTION}

The development of market economy renders the growing-up of the industrial clusters in China. As is known, industrial clusters, as a new kind of economic form, works effectively in the modern economy because of its division of labour and the advantages of cluster effects. Limited by its high cost, high risk and short lifespan of products, the high technology enterprises have to take advantage of industrial clusters to make up for its limitations and to improve its development potentials. Although the industrial clusters in Leshan are developing very fast, there are still many problems which restrict the development of clusters. One of the main problems is how to apply the proper performance evaluation criteria for the hightechnology industrial clusters and come up with the coping measures to enhance their healthy development.

\section{THE FEATURES OF THE HIGH-TECHNOLOGY ENTERPRISES}

A high technology enterprise is identified from three aspects: the ratio of research expense, the quality of hightech products, and the human capital, which are the key factors affecting the competitiveness of the high-tech enterprises.

The distinct features of the high-tech enterprises are that they usually invest a lot of capitals in research and human resources, they are marked by the advancement of knowledge and technologies, and they face high risks in the early development, while getting high profits in their later development and push the local economic development effectively. In the process of developing, the high-tech enterprises would obtain various abilities for their survival and development in terms of their surroundings. And that the products are new, high-tech, and quickly updated requires that the enterprises should have a good ability to research and development, and collective spirit of innovation, quick response to the market changes, and the quick and excellent system for marketing and services.

\section{THE PRINCIPLES FOR THE PERFORMANCE EVALUATION CRITERIA FOR THE HIGH-TECH INDUST RIAL CLUSTERS IN LESHAN}

The performance evaluation criteria of the high-tech industrial clusters in Leshan are established to show the competitiveness of enterprises by analyzing the degree of resource utilization of these enterprises in the same line. And in order to ensure the validity of these criteria and that the evaluation results should reflect the reality of industrial clusters comprehensive, objective and accurate, the criteria should obey the following principles:

(1) Scientific. The criteria should describe the advantages of industrial clusters scientifically and accurately, and these criteria should be representative and simple to show the reasonable system of the industrial clusters, for they must reflect the features of the high-tech industry, such as high investment, high risk and high profits, and the features of industrial clusters.

(2) Systematic. The criteria should be an organic whole to evaluate the performance comprehensively and scientifically, after taking into consideration the relationships, the hierarchy structure, and targets of each sub-criterion and matching of criteria.

(3) Practical. The performance evaluation criteria for industrial clusters not only pay attention to the development of industrial clusters and give suggestions for the management and decision-making of industrial clusters, but also make the data for evaluation available and easy to be collected, and reliable to be applied and dealt with.

(4) Stable. The stability of the performance evaluation criteria should be taken into consideration, which makes the application of these criteria. To apply these criteria is to evaluate one enterprise repetitively and compare the results of these evaluations; then, the criteria should try to avoid the great difference of the results and irregular changes of the results. Meanwhile, the criteria should also make allowance for the horizontal comparability of enterprises and the vertical comparability of one enterprise.

(5) Universal. The criteria should be applied to the enterprises in the same line universally and meet the needs of evaluation of these enterprises practically and ideally. 
Otherwise, the criteria would be restricted to a certain field which affects the results of the performance evaluation.

(6) Compatible. The criteria should be applied to different research objects and be adjusted to different situations according to the specific surroundings, and form different standard systems for different targets.
3. The Performance Evaluation Criteria for the Hightech Industrial Clusters in Leshan.

IV. THE PERFORMANCE EVALUATION CRITERIA FOR THE HIGH-TECH INDUST RIAL CLUSTERS IN LESHAN.

\section{The Criteria of the Performance Evaluation for the High-tech Industrial Clusters}

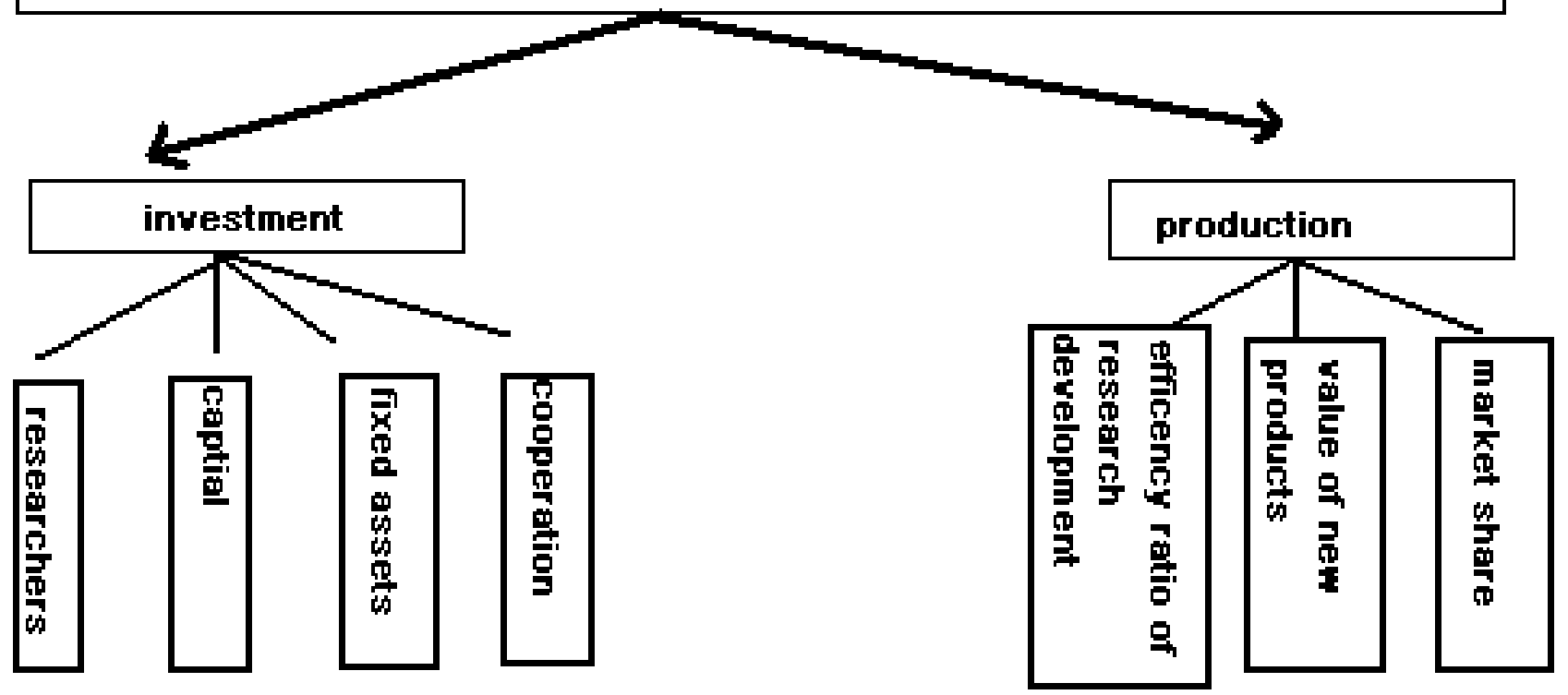

Figure 1. Performance Evaluation Criteria for the High-Tech Industrial Clusters in Leshan

The performance of industrial clusters should be evaluated from two sides: one is the resource investment of enterprises in an industrial cluster; and another is the products. Here, researchers try to establish the criteria as shown above, based on the investment of the researchers, capitals, fixed assets and cooperation among enterprises and the products and services enterprises provide.

Researchers in the above figure are to the ratio of researchers in an enterprise, in order to reflect the investment of human resource in technology of an enterprise. Capitals are used to show how much the cost is to marketing, and how many the profits an enterprise can get. The less this criterion is, the more profits an enterprise can get. Fixed assets can reflect the profitability and efficiency of the fixed assets of high-tech enterprises. The cooperation among enterprises displays the degree of cooperation and correlation of the enterprises in a industrial cluster. The bigger the value of this criterion is, the greater degree of cooperation among enterprises is.

As for the production, researchers should take time lags for the research and development of a product, and then adopt that the efficiency ratio of research and development should be measured by the percentage of three-year profits nearly in the investment of research and development. This criterion reflects the output level of a high-tech enterprise in research. The higher the efficiency ratio of research and development is, the higher output level an enterprise has, and the stronger its competitiveness is. The value of new products shows the output level of an enterprise in developing new products, and in its capital investment. The market share shows the control ability in market, which clearly reflects the competitiveness of a high-tech enterprise in the quality and services of products.

\section{ON THE COMPREHENSIVE PERFORMANCE EVALUATION OF HIGH-TECH INDUSTRIAL CLUSTERS BASED ON DEA}

The comprehensive performance evaluation should include the selection of models and patterns of evaluation.

The object of the DEA is the decision making unit. The enterprises in the high-tech industrial clusters can be regarded as decision making units, which have their own input and output, , and they try their best to achieve their common goals in the process of turning the input to the output, that is, improve the efficiency in using resources and strengthening the competitiveness of the industrial cluster the enterprises belong to. The DEA can be applied to evaluate and give information on how to optimize the efficiency when using the same kind of resources in an enterprise at the high-tech industrial cluster.

The patterns of evaluation of the DEA in the performance evaluation of high-tech industrial clusters are as follows:

(1) To set the goals of evaluation: the basic function of DEA method is to evaluate, therefore, it is necessary to analyze and evaluate the specific objectives, which is the main basis for the establishment of evaluation index system and the choice of DEA model. This paper uses DEA method to evaluate the high and new technology enterprise cluster enterprises of the same type of resources utilization efficiency for high and new technology enterprise cluster. The efficiency of using resources more high means cluster can spend to get more output with 
fewer resources, illustrate the development of high and new technology enterprise cluster is more reasonable; on the contrary, the efficiency is low. Can be seen, the use of DEA "relative effectiveness" evaluation, can achieve the purpose of this research.

(2) To select the decision making units: select DMU. From the perspective of technology and experience, DEA number of DMU has the following requirements, a reference set of DMU should have the same type "characteristics, that is the same input and output indicators, with the same external environment, with the same tasks and goals; the second is usually considered the reference element set the number of not less than the input output index number of times is appropriate.

(3) To establish the criteria for input and output: input output evaluation index system from first principles is a reflection of the objective and the content of evaluation; secondly, from the technology should avoid internal indicators of a strong linear relationship with input and output sets, while considering the indices of diversity and index of accessibility. In DEA application of high and new technology enterprise cluster development pattern evaluation, index system as described in the previous section input indicators include: Enterprise Science and technology personnel proportion, profit rate of cost ratio, fixed assets, enterprise cooperation ability; output indicators include: R \& D input efficiency ratio, the output value of new products, market share. Of course, the DEA evaluation results are different under different indicators. Therefore, researchers should take into account the DEA evaluation results with the change of the index system and the change of the value of the information.

(4) To select the model of the DEA: DEA model has many forms, in the evaluation of high-tech enterprise cluster in the same type of enterprise to the resource utilization efficiency, the main choice of evaluation scale and technology effective $C^{2} \mathrm{R}$ model. At the same time, according to the research purposes of the problem can also choose other DEA model or other methods, in order to obtain more objective and comprehensive conclusions.

(5) To apply the model to evaluate: the DEA evaluation analysis includes data collection and collation, model solving and analysis of the evaluation results. In data envelopment analysis (DEA) based on the results of actual analysis is one of the important links in data envelopment analysis (DEA), this work to knowledge and experience and problems of practical background and relevant experts combined if DEA evaluation results through the test of practice, can provide useful information for decision makers; on the contrary, the need to re adjust the evaluation index system or other evaluation model selection.

(6) To get the evaluation results: through modeling and solving the DEA method to obtain the following information: effect relationship between the relative effectiveness of the DEA efficiency of each DMU, relative returns to scale, relative efficiency of production frontier and each DMU in the projection, the DMU and each input (output) indicators, indicators of each DMU. According to the above information, combined with the grasp of understanding and experience of the practical problems in the background, can find out the impact of high and new technology enterprise cluster enterprises of the same type of resources use efficiency of resistance and restricting factors, formulate scientific and reasonable high technology enterprise clusters development strategy.

\section{CONCLUSIONS}

The DEA is mainly to evaluate the performance of high-tech industrial clusters in Leshan from the efficiency in using resources and allocation of resources of enterprises. From the comparison of results, it is found that the cooperation of enterprises in industrial clusters is not enough, and there are obvious differences among enterprises, which shows that although their scale is reasonable, they still need to get improved. Meanwhile, these results also show that the development of industrial clusters in Leshan is restricted by inadequate research investment, little cooperation between research institutions or universities and enterprises, shortage of researchers in enterprises and unreasonable allocation in research resources. For these problems, the paper thus tries to give the following suggestions.

(1) Enterprises should invest more in research and training of researchers by itself. Only in this way can enterprises establish their research institutions to get improved in their own ability in research and to train their researchers regularly to cultivate their research teams.

(2) Enterprises should work with the research institutions or universities. The production-study-research cooperative innovation of an enterprise is the best way to integrate the internal and external factors of enterprises in the industrial clusters. On one hand, it will enhance the exchanges in innovation of enterprises in the cluster, and help the leading enterprise play its part. On the other hand, the cooperation of enterprises with research institutions or universities is a way to establish training bases or improve the exchanges in research. The enterprises in the clusters should try to interact with the enterprises out of their clusters, which help introduce new products and cooperate in new technologies to get more profits.

(3) The government should make laws to guide and encourage the enterprises of clusters in innovation, prize the leading enterprises, give favorable policies to those who have made great contributions to tax, and protect the patented technologies and innovative achievements to make sure the development of industrial clusters.

(4) The government should give full play to the functions of the government to promote the establishment of high-tech enterprise clusters and perfect. Theoretically speaking, enterprise clusters shall generate the power source to the guiding role of the market, and the government shall not play a major role. However, since the development of high and new technology enterprise cluster in Leshan City is still in the initial stage, the government can play the market role and support cluster development in many fields during the process of development,. First of all, the government should focus on the development of high and new technology enterprises on the bas is of the requirements of infrastructure, high quality and high quality to build the infrastructure in the new zone, with the environment to attract dilute policy. The development of high-tech enterprise clusters depends on the government's construction and improvement of urban transportation, communication and other infrastructure. Second, the government should accelerate the reform of the system to 
support scientific and technological progress. In the investment system, the government should give full play to the guiding role of government investment in science and technology, learn from the experience of Silicon Valley, take measures such as developing government support key enterprises, increase the high-tech enterprises in Leshan City, es pecially make support efforts in small and mediu msized high-tech enterprises, form the government-oriented enterprises as the main body and the banks as backing, and build other inputs for science and technology of multi forms and multi-channel investment system. Besides, the government should provide a strong institutional guarantee for the development of high-tech enterprise clusters.

(5) A cluster in the leading industry promote the division of labor and cooperation among enterprises: in Leshan City High-tech Zone with similar industrial structure, the assimilation phenomenon is seriously emerged in the development strategy, the High-tech Zone shall give full play to the advantages of local resources, build a unique technology environment, and gradually establish their own superiority characteristic industry. In a region, each enterprise cluster should concentrate on a dominant industry and special products of key construction projects, support the development and expand intra regional social collaboration network, and form a distinctive cluster of high-tech enterprises. Through unified planning, a reasonable division of labor should be formed, in order to avoid the low level of competition between the high and New Technology Industrial Development Zone, and increase the industrial connection with each other. As a result, high technology enterprise may have the innovation power with high efficiency and good insurance.

(6) An enterprise should be managed according to its rules. Besides, the enterprise shall improve its management ability, encourage innovation, make the structure of the enterprise more reasonable, and promote its scale efficiency, which would steadily boost the overall efficiency in innovation of the whole industrial cluster.

\section{REFERENCES}

[1] Li Baizhou, Fudan. Jiyu DEA de Gaoxin Jishu Qiye Jiqun Xiaolv Pingjia Yanjiu [J]. Science \& Technology Progress and Policy, 2008 (1): 133-134.

[2] Guo Yin. A Study of Industrial Clusters Performance Evaluation based on DEA Method [D]. Xi' an University of Architecture and Technology, 2012.

[3] Shi Yanwen \& Li Erling. The Evaluation and Analysis of Agricult ural Innocation Performance Based on DEA [J]. Henan Science, 2012(10).

[4] Fudan. The Research on Development Pattern of High Technology Enterprise Clusters [D]. Ha'rbin Engineering University, 2006.

[5] Guo Peili. DEA-based Evaluation of Core Enterprise's Performance in Industrial cluster [D]. Zhengzhou University, 2011.

[6] Zhao Guang. Research on Innovation Capability of High-tech Enterprise in the Cluster [D].North China University of Technology, 2009.

[7] Wang Shanshan. Research on the comprehensive advantages of high tech enterprise cluster [D]. Harbin University of Science and Technology, 2008.

[8] Xu Shuyun Research on the comprehensive advantages of high tech enterprise cluster [D]. Hunan Normal University, 2014.

[9] Kuang Wenfen. Research on the technology innovation of high tech enterprise cluster in innovation network [D]. Xiangtan University, 2009.

[10] Liu Yuanyuan. Research on cluster upgrading of high tech enterprises based on global value chain [D]. Harbin University of Science and Technology, 2008.

[11] Wang Jie. Research on innovation network of high tech enterprise cluster based on patent Perspective [D]. Harbin University of Science and Technology, 2010.

[12] Sun Xiaoyu. Research on dynamic strategic performance evaluation of high tech Enterprises [D]. Harbin University of Science and Technology, 2009. 